\title{
Study of interfacial reactions and phase stabilization of mixed Sc, Dy, Hf high- $k$ oxides by attenuated total reflectance infrared spectroscopy
}

\author{
A. Hardy a,b, C. Adelmann ${ }^{c}$, S. Van Elshocht ${ }^{c}$, H. Van den Rul ${ }^{\text {a,b }}$, M.K. Van Bael ${ }^{\text {a,b,*, }}$ \\ S. De Gendt ${ }^{\mathrm{c}, \mathrm{e}}$, M. D’Olieslaeger ${ }^{\mathrm{b}, \mathrm{d}}$, M. Heyns ${ }^{\mathrm{c}, \mathrm{e}}$, J.A. Kittl ${ }^{\mathrm{c}}$, J. Mullens ${ }^{\mathrm{a}}$ \\ ${ }^{a}$ Hasselt University, Inorganic and Physical Chemistry - IMO, Diepenbeek, Belgium \\ ${ }^{\mathrm{b}}$ IMEC vzw, Division IMOMEC, Diepenbeek, Belgium \\ ${ }^{\mathrm{c}}$ IMEC vzw, Heverlee, Belgium \\ ${ }^{\mathrm{d}}$ Hasselt University, Institute for Materials Research, Diepenbeek, Belgium \\ ${ }^{\mathrm{e}}$ KULeuven, Department of Chemistry, Heverlee, Belgium
}

\section{A R T I C L E I N F O}

\section{Article history:}

Received 19 March 2009

Received in revised form 27 April 2009

Accepted 28 April 2009

Available online 3 May 2009

Keywords:

ATR-FTIR

Hafnia

Scandate

Rare earth

High permittivity

\begin{abstract}
A B S T R A C T
Grazing angle attenuated total reflectance Fourier transform infrared spectroscopy is applied to study ultrathin film $\mathrm{Hf}^{4+}, \mathrm{Sc}^{3+}$ and $\mathrm{Dy}^{3+}$ oxides, due to its high surface sensitivity. The (multi)metal oxides studied, are of interest as high- $k$ dielectrics. Important properties affecting the permittivity, such as the amorphous or crystalline phase and interfacial reactions, are characterized.

$\mathrm{Dy}_{2} \mathrm{O}_{3}$ is prone to silicate formation on $\mathrm{SiO}_{2} / \mathrm{Si}$ substrates, which is expressed in $\mathrm{DySCO}_{3}$ as well, but suppressed in $\mathrm{HfDyO}_{x}$. $\mathrm{Sc}_{2} \mathrm{O}_{3}, \mathrm{HfSCO}_{x}$ and $\mathrm{HfO}_{2}$ were found to be stable in contact with $\mathrm{SiO}_{2} / \mathrm{Si}$. Deposition of $\mathrm{HfO}_{2}$ in between $\mathrm{Dy}_{2} \mathrm{O}_{3}$ or $\mathrm{DySCO}_{3}$ and $\mathrm{SiO}_{2}$, prevents silicate formation, showing a buffer-like behavior for the $\mathrm{HfO}_{2}$.

Doping of $\mathrm{HfO}_{2}$ with Dy or Sc prevents monoclinic phase crystallization. Instead, a cubic phase is obtained, which allows a higher permittivity of the films. The phase remains stable after anneal at high temperature.
\end{abstract}

(c) 2009 Elsevier B.V. All rights reserved.

\section{Introduction}

Downscaling of CMOS transistors has allowed continuously increasing device speed and improved performance. As a consequence of the miniaturization the gate dielectric, $\mathrm{SiO}_{2}$, thickness has been decreased strongly. Recently, commercial production has switched to alternative gate dielectric materials with a higher permittivity than $\mathrm{SiO}_{2}(k=3.9)$, in order to control the leakage current. Due to the higher permittivity, the physical thickness is higher than the effective oxide thickness (EOT), which allows avoiding electron tunneling through the dielectric oxide $[1,2]$.

Hafnium based materials such as amorphous $\mathrm{HfO}_{2}(k \sim 22$ [3] $)$ and $(\mathrm{Hf}, \mathrm{Si}) \mathrm{O}_{2}$ mixed compositions have recently received a great deal of attention. The amorphicity or crystalline phase strongly affects the permittivities which are achieved. The thermodynamically stable crystal structure of $\mathrm{HfO}_{2}$ at room temperature is

\footnotetext{
* Corresponding author at: Hasselt University, Inorganic and Physical Chemistry, Agoralaan building D, B-3590 Diepenbeek, Belgium. Tel.: +32 112683 07; fax: +3211268301.

E-mail addresses: an.hardy@uhasselt.be (A. Hardy), marlies.vanbael@uhasselt.be (M.K. Van Bael).
}

monoclinic and is characterized by a $k \sim 16$ [4]. Tetragonal and cubic high temperature phases on the other hand show much higher permittivities ( $k \sim 70$ and 29 respectively [4]). These phases have been shown to be stabilized by doping $\mathrm{HfO}_{2}$ with lanthanides [5-8]. Besides Hf based materials, lanthanide scandates are reported to be promising as high- $k$ dielectrics, due to their high permittivity $(>20)$ and crystallization resistance up to high temperatures, which is explained by silicate formation $[6,9,10]$.

Independent of the high- $k$ material, MOS device performance is always affected by reactions at the interface with the $\mathrm{SiO}_{x} / \mathrm{Si}$ substrate, such as silicate formation or regrowth of interfacial $\mathrm{SiO}_{x}$. These interfacial layers can be characterized by a lower permittivity and thus lead to undesirable increase of the EOT of the stack. However, often a very thin starting $\mathrm{SiO}_{x}$ is required to obtain layer nucleation e.g. in atomic layer deposition [11-13], and therefore cannot be avoided. The control of its thickness during further processing then remains crucial [1].

The ultralow thickness of the high- $k$ layers $(<10 \mathrm{~nm})$, necessitates the use of highly sensitive characterization techniques, such as grazing incidence X-ray diffraction (XRD), cross section transmission electron microscopy (TEM), TOF-SIMS (time of flight secondary ion mass spectrometry), or XPS (X-ray photoelectron spectroscopy). FTIR (Fourier transform infrared 
spectroscopy) allows the detection of metal oxide as well as silicate vibrations. Normal transmission measurements are insufficiently sensitive, but the surface sensitivity can be greatly enhanced in attenuated total reflectance (ATR) [14]. The sensitivity enhancement depends on the angle of incidence, the thickness of the air gap and the dielectric constants of the ATR crystal and the film's substrate $[15,16]$.

Here, we apply grazing angle attenuated total reflectance Fourier transform infrared (GATR-FTIR) to several high- $k$ films of recent interest, Hf, Dy and Sc oxides, which were deposited by atomic vapour deposition (AVD) or atomic layer deposition (ALD) for high quality film growth with atomic precision. The results contribute to the explanation and understanding of the dielectric properties, demonstrating the potential of GATR-FTIR in high- $k$ characterization.

\section{Material and methods}

All the high- $k$ films were grown by AVD (Aixtron Tricent ${ }^{\mathrm{TM}}$ reactor) on Si ( 100 ) wafers as described elsewhere $[6,9,17,18]$, with $550{ }^{\circ} \mathrm{C}$ susceptor temperature, unless indicated otherwise. Precursors used were tris(6-ethyl-2,2-dimethyl-3,5-decanedionato)dysprosium [Dy(EDMDD) 3 ], tris(6-ethyl-2,2-dimethyl-3,5decanedionato) scandium [Sc(EDMDD $\left.)_{3}\right]$, and bis(tert-butoxide) bis(methoxymethyl propanoxide) hafnium $\mathrm{Hf}\left(\mathrm{O}^{\mathrm{t}} \mathrm{Bu}\right)_{2}(\mathrm{mmp})_{2}$ combined with molecular $\mathrm{O}_{2} \cdot \mathrm{SiO}_{2}$ starting oxide was obtained with a thickness of $1.1 \mathrm{~nm}$ by chemical oxidation $\left(\mathrm{H}_{2} \mathrm{O} / \mathrm{O}_{3}\right)$, while thicker $\mathrm{SiO}_{2}$ was obtained by rapid thermal oxidation. Film thicknesses were determined by X-ray reflectivity. The compositions of the films are determined by X-ray photoelectron spectroscopy $\left(\mathrm{HfDyO}_{x}, \mathrm{HfScO}_{x}\right)$ and Rutherford backscattering spectroscopy $\left(\mathrm{DyScO}_{3}\right)$. The doped $\mathrm{HfO}_{2}$ films contain $10 \%$ Dy or $\mathrm{Sc}$ $(90 \% \mathrm{Hf})$ and the $\mathrm{DyScO}_{3}$ consists of $50 \%$ Dy and $50 \%$ Sc unless specified otherwise (percentages ignoring O, e.g. Dy/Dy + Hf). Post deposition anneals were carried out at $1000{ }^{\circ} \mathrm{C}$ in $\mathrm{N}_{2}$ or $\mathrm{O}_{2}$ for $60 \mathrm{~s}$.

Sample preparation for grazing angle attenuated total reflectance Fourier transform infrared measurement consists of cleaving square pieces $(2 \mathrm{~cm} \times 2 \mathrm{~cm}$ to $3 \mathrm{~cm} \times 3 \mathrm{~cm})$ from the wafers. GATR-FTIR spectroscopy was carried out by means of a $65^{\circ}$ single reflection Ge-ATR (supplied by Harrick), placed in the sample compartment of an FTIR spectrometer (Bruker, Vertex 70). The compartment and the GATR-cell were flushed with dried air and $\mathrm{N}_{2}$ respectively. Intimate contact between the sample and the Ge crystal is obtained by applying $56 \mathrm{oz} \mathrm{in.}{ }^{-1}$ of pressure. Spectra were referenced against the clean Ge crystal and obtained with a spectral resolution of $4 \mathrm{~cm}^{-1}$, in a spectral range from 4000 to $600 \mathrm{~cm}^{-1}$. For the spectra, the ATR signal $=($ absorbance $\times$ wavenumber)/1000 is shown. Since the penetration depth is inversely proportional to the wavenumber this normalizes the spectra to a constant penetration depth. In between the samples, blank $1.2 \mathrm{~nm} \mathrm{SiO}_{x} / \mathrm{Si}$ samples were measured, showing no changes in the Ge crystal's state, such as scratches, which would affect the spectra and interfere with the comparison of different samples.

\section{Results and discussion}

\subsection{Monometal oxides}

\subsubsection{Phase identification of hafnium oxide}

The permittivity of the $\mathrm{HfO}_{2}$ layers studied here was determined to be 16 , as published elsewhere [6]. This value can be characteristic either for amorphous or monoclinic $\mathrm{HfO}_{2}$.

$\mathrm{HfO}_{2}$ layers with thicknesses of 3,8 and $18 \mathrm{~nm}$ on $1.1 \mathrm{~nm} \mathrm{SiO}_{2} / \mathrm{Si}$ have been characterized and their spectra are compared to a blank $\mathrm{SiO}_{x} / \mathrm{Si}$ substrate (Fig. 1a). Band assignments and interpretations are as follows. At 1240 and $1065 \mathrm{~cm}^{-1}$ the longitudinal (LO) and
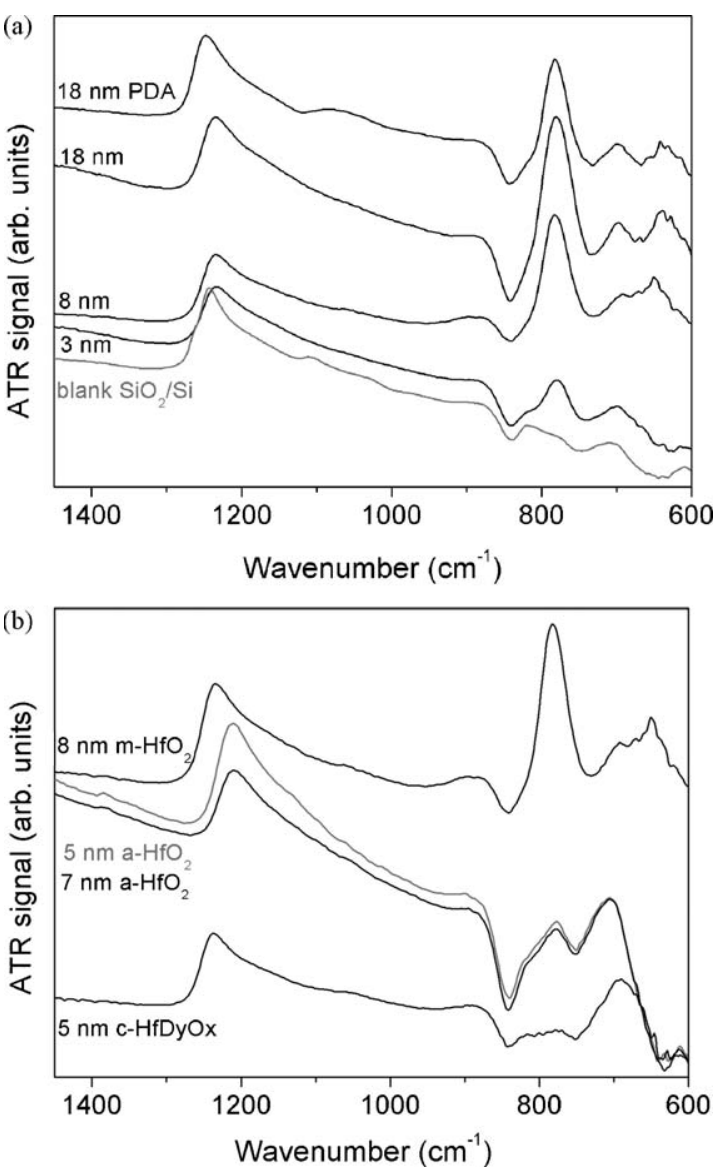

Fig. 1. GATR-FTIR spectra of (a) monoclinic $\mathrm{HfO}_{2}$ as function of thickness, (b) comparison of different phases of (stabilized) hafnia in films of comparable thickness (a: amorphous, c: cubic, m: monoclinic).

transverse optic (TO) band of $\mathrm{SiO}_{2}$ are found [15]. At $1100 \mathrm{~cm}^{-1} \mathrm{Hf}-$ O-Si vibrations would be expected [19], but comparison with the blank substrates shows that any intensity in this area is due to the $\mathrm{SiO}_{2}$ from the substrate [20]. At $900 \mathrm{~cm}^{-1}$ both the blank substrate and the $\mathrm{HfO}_{2}$ films show slightly increased intensity, which might be ascribed to $\mathrm{Si}-\mathrm{OH}$ [21]. The band at $780 \mathrm{~cm}^{-1}$ can be ascribed to the monoclinic crystal phase of $\mathrm{HfO}_{2}$, which forms a doublet together with the weaker feature at $690-700 \mathrm{~cm}^{-1}$. Theory predicts this doublet to be situated at $780 / 694 \mathrm{~cm}^{-1}$ and $683 / 634 \mathrm{~cm}^{-1}$ [4], and it has been ascribed experimentally to peaks at $760 \mathrm{~cm}^{-1}$ [7] or 752 and $635 \mathrm{~cm}^{-1}[16,22,23]$. Based on the presence of this vibration around $780 \mathrm{~cm}^{-1}$ in the spectra of $\mathrm{HfO}_{2}$ films of all thicknesses studied, it can be concluded that all of these films contain monoclinic $\mathrm{HfO}_{2}$.

Post deposition anneal in $\mathrm{O}_{2}\left(\mathrm{PDA}, 1000{ }^{\circ} \mathrm{C}\right.$ ) does not affect the $\mathrm{HfO}_{2}$ band position and relative intensities. There is no evidence for $\mathrm{Hf}-\mathrm{O}-\mathrm{Si}$ vibrations around $1100 \mathrm{~cm}^{-1}$. It can be concluded that the anneal does not affect the $\mathrm{HfO}_{2}$ phase present, nor leads to interfacial silicate formation.

Theoretically, it is impossible to observe the bands for the higher- $k$ cubic phase of $\mathrm{HfO}_{2}$, situated at $286 \mathrm{~cm}^{-1}$, in the measurable range of Ge-ATR [4]. Nonetheless, a single band at $695 \mathrm{~cm}^{-1}$, in absence of a feature at $780 \mathrm{~cm}^{-1}$, has been ascribed to cubic $\mathrm{HfO}_{2}$, because electron diffraction showed the presence of this phase in the samples [7]. The authors however did not demonstrate the absence of a portion amorphous phase, which is also reported to show a single band of similar shape in this wavenumber region of $690 \mathrm{~cm}^{-1}[3,16,24]$. The presence or absence of a shoulder to the high wavenumber side of this band, 
is regarded as indicative of amorphous and cubic $\mathrm{HfO}_{2}$ respectively [25]. Since literature reports appear contradictive as far as distinction of cubic and amorphous $\mathrm{HfO}_{2}$ is concerned, we studied XRD-amorphous $\mathrm{HfO}_{2}$ films, deposited by ALD at $250{ }^{\circ} \mathrm{C}$ using $\mathrm{HfCl}_{4}$ and $\mathrm{H}_{2} \mathrm{O}$ [26], by GATR-FTIR as well (Fig. 1b). The comparison shows a clear distinction between the amorphous, cubic and monoclinic phase. Monoclinic $\mathrm{HfO}_{2}$ is distinguished by a strong band $\sim 780 \mathrm{~cm}^{-1}$ and a much less intense vibration around $700 \mathrm{~cm}^{-1}$. $\mathrm{HfDyO}_{x}$ shows a feature around $690 \mathrm{~cm}^{-1}$ and very low intensity around $780 \mathrm{~cm}^{-1}$. Due to the peak half width in XRD being of the order of or larger than the peak splittings expected, there is no evidence for tetragonal phase, and therefore the $\mathrm{HfDyO}_{x}$ layers were assigned as cubic phase. Amorphous $\mathrm{HfO}_{2}$ is characterized by a vibration around 780 and $700 \mathrm{~cm}^{-1}$ as well, but the relative intensities of the bands are clearly different from c$\mathrm{HfO}_{2}$ and $\mathrm{m}-\mathrm{HfO}_{2}$. Note that by comparison of similar layer thicknesses, optical effects as a function of thickness are cancelled out from the discussion.

In conclusion, the GATR-FTIR results shown here, allow to ascribe the experimentally observed permittivity of 16 [6] to the monoclinic crystal phase of these $\mathrm{HfO}_{2}$ layers. This is in accordance with X-ray diffraction patterns reported in Ref. [6]. In literature [24], ultrathin films are reported to remain amorphous, but here a $3 \mathrm{~nm}$ thick film was crystalline, monoclinic phase. The GATR-FTIR is shown to be more sensitive to monoclinic $\mathrm{HfO}_{2}$ than deep-UV micro-Raman spectrometry, where it was not distinguished from the noise in a $3 \mathrm{~nm}$ thick $\mathrm{HfO}_{2}$ layer.

\subsubsection{Interfacial reactions of dysprosium and scandium oxide}

$10 \mathrm{~nm}$ thick $\mathrm{Dy}_{2} \mathrm{O}_{3}$ monometal oxide films were studied for comparison with $\mathrm{HfDyO}_{x}$ and $\mathrm{DyScO}_{3}$. The spectra of dysprosium oxide grown on $1.1 \mathrm{~nm} \mathrm{SiO} 2,20 \mathrm{~nm} \mathrm{SiO}$ and $12 \mathrm{~nm} \mathrm{HfO}_{2}$ are shown in Fig. 2, and are compared to the respective blank substrates. For the thin $\mathrm{SiO}_{x}$ substrate it is clear that the $\mathrm{SiO}_{x}$ characteristic band at $1240 \mathrm{~cm}^{-1}$ disappears from the spectrum and a strong, new band occurs with a peak maximum at $1017 \mathrm{~cm}^{-1}$. The latter band is ascribed to Si-O-Dy vibrations. Bond formation with Dy, which is heavier than $\mathrm{Si}$, shifts the band to lower frequencies compared to the $\mathrm{Si}-\mathrm{O}-\mathrm{Si}$ band [27]. This demonstrates strong silicate formation, which apparently consumes the $\mathrm{SiO}_{2}$ entirely. Typical Dy-O vibrations are not detected as they are situated below $600 \mathrm{~cm}^{-1}$ e.g. 550 or $555 \mathrm{~cm}^{-1}$ with a broad shoulder at $580 \mathrm{~cm}^{-1}$, is expected [28-31]. Chemical instability of $\mathrm{Dy}_{2} \mathrm{O}_{3}$ by reaction with $\mathrm{H}_{2} \mathrm{O}$ or $\mathrm{CO}_{2}$ from the ambient probably did not occur, as (bi)carbonate (3727, 3711, $1661,1634 \mathrm{~cm}^{-1}$ [32]) and hydroxide bands $\left(3600 \mathrm{~cm}^{-1}\right.$ [33]) were not detected in the spectra. This can be related to a stronger stability of $\mathrm{Dy}_{2} \mathrm{O}_{3}$ against these reactions compared to other $\mathrm{Ln}_{2} \mathrm{O}_{3}$ [34]. Deposition of $10 \mathrm{~nm} \mathrm{Dy}_{2} \mathrm{O}_{3}$ on $20 \mathrm{~nm} \mathrm{RTO} \mathrm{SiO}_{2}$ clearly shows a very strong band in the same wavenumber region as the $\mathrm{Si}-\mathrm{O}-\mathrm{Dy}$ band for the $\mathrm{Dy}_{2} \mathrm{O}_{3} / 1.1 \mathrm{~nm} \mathrm{SiO}$ film. For the blank $10 \mathrm{~nm} \mathrm{SiO}_{2}$ substrate, the intensity around $1050 \mathrm{~cm}^{-1}$ is strong as well, and the band shape and position of $\mathrm{SiO}_{2}$ is strongly dependent on the $\mathrm{SiO}_{2}$ thickness due to optical effects of interference [15]. However, the intensity of the band at $\sim 1050 \mathrm{~cm}^{-1}$ is relatively much stronger compared to the LO $\mathrm{SiO}_{2}$ band at $1225 \mathrm{~cm}^{-1}$ for the $\mathrm{Dy}_{2} \mathrm{O}_{3}$ film than for the blank $10 \mathrm{~nm} \mathrm{SiO}_{2}$ substrate. This suggests that silicate formation occurs in the $\mathrm{Dy}_{2} \mathrm{O}_{3} / 20 \mathrm{~nm} \mathrm{SiO}_{2}$ film as well and is more intense than for $1.1 \mathrm{~nm} \mathrm{SiO}_{2} .10 \mathrm{~nm} \mathrm{Dy}_{2} \mathrm{O}_{3}$ films deposited on $12 \mathrm{~nm} \mathrm{HfO}_{2}$ on the other hand, showed $\mathrm{SiO}_{2} \mathrm{LO}$ and TO bands similar to a blank substrate and no evidence for Dy-O-Si vibrations. The monoclinic phase of $\mathrm{HfO}_{2}$ is demonstrated by its characteristic vibration at $780 \mathrm{~cm}^{-1}$. It can be concluded that $\mathrm{HfO}_{2}$ acts as an efficient barrier, preventing silicate formation of $\mathrm{Dy}_{2} \mathrm{O}_{3}$.
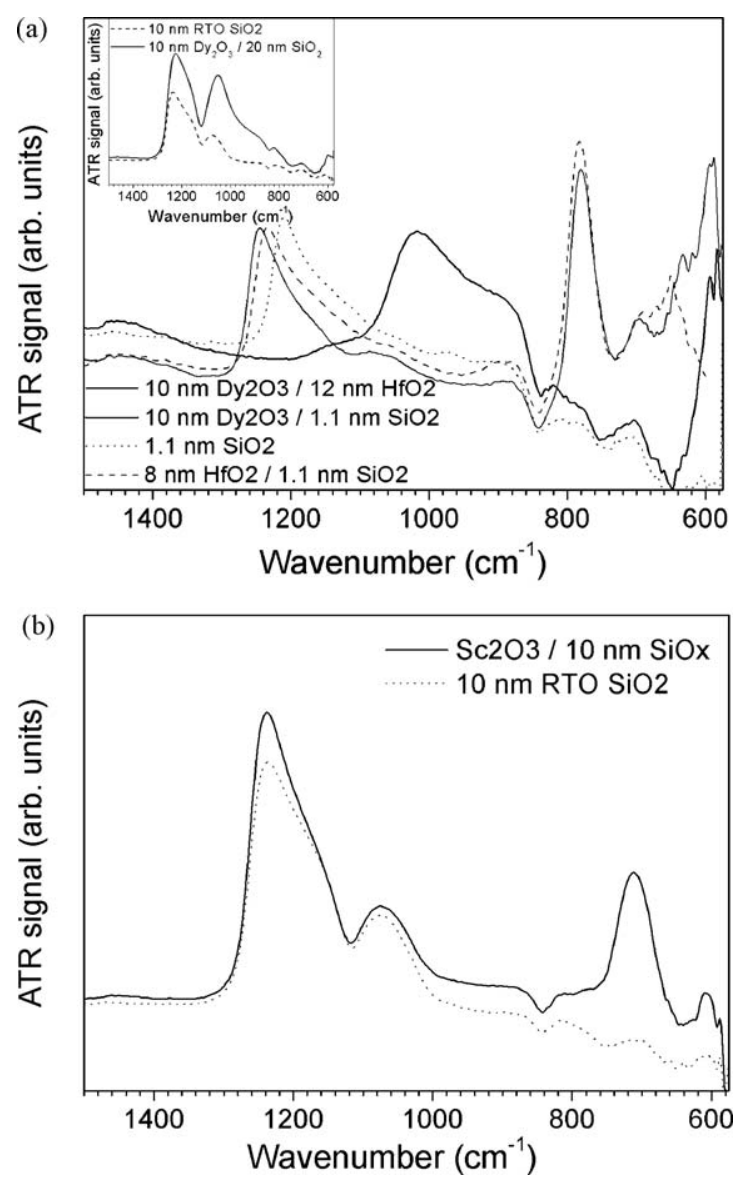

Fig. 2. (a) $10 \mathrm{~nm} \mathrm{Dy}_{2} \mathrm{O}_{3}$ on different substrates as indicated, (b) $10 \mathrm{~nm} \mathrm{Sc} \mathrm{O}_{3} / 10 \mathrm{~nm}$ $\mathrm{SiO}_{2}$.

In contrast with $\mathrm{Dy}_{2} \mathrm{O}_{3}$, a $10 \mathrm{~nm} \mathrm{Sc}_{2} \mathrm{O}_{3}$ film on $10 \mathrm{~nm} \mathrm{RTO} \mathrm{SiO}_{x}$ did not show any silicate formation, as the relative intensity of $\mathrm{SiO}_{2}$ TO and LO was identical to the blank substrate. This is in accordance with the reported thermodynamic stability of $\mathrm{Sc}_{2} \mathrm{O}_{3}$ in contact with $\mathrm{SiO}_{2}$ [35]. Vibration bands are observed at 711 and $609 \mathrm{~cm}^{-1}$, which should be ascribed to $\mathrm{Sc}_{2} \mathrm{O}_{3}$. Comparison with literature on the other hand, shows expected bands at 625 or $635 \mathrm{~cm}^{-1}[28,29]$ for C-type oxide [36]. The discrepancy is neither related to an amorphous nature of the layer, as its crystallinity was evidenced by XTEM (not shown), nor to a difference in crystal structure as $\mathrm{Sc}_{2} \mathrm{O}_{3}$ has no known polymorphs, only the cubic bixbyite phase [37].

\subsection{Multimetal oxides}

\subsubsection{Phase identification and interfacial reactions of dysprosium and scandium doped hafnia}

Doping hafnia with lanthanides has been reported to stabilize the cubic phase in $\mathrm{HfO}_{2}$, leading to higher permittivities and prolonging its applicability for commercial purposes [6]. Here, the phase stabilization of cubic hafnia by doping with Dy and Sc is studied by GATR-FTIR.

In Fig. 3 spectra of as-deposited $\mathrm{HfDyO}_{x}$ films with thicknesses of 3, 5 and $18 \mathrm{~nm}$ are shown. Spectra are shifted along the ordinate for clarity. As the band assignments are the same as for hafnia itself, it is clear from Fig. 3 that the doping with Dy has prevented the crystallization of monoclinic hafnia, indicated by the absence of a vibration band around $780 \mathrm{~cm}^{-1}$. Instead, either an amorphous or a cubic phase has been formed, as indicated by the band around $695 \mathrm{~cm}^{-1}$, and the latter was confirmed by X-ray diffraction as 


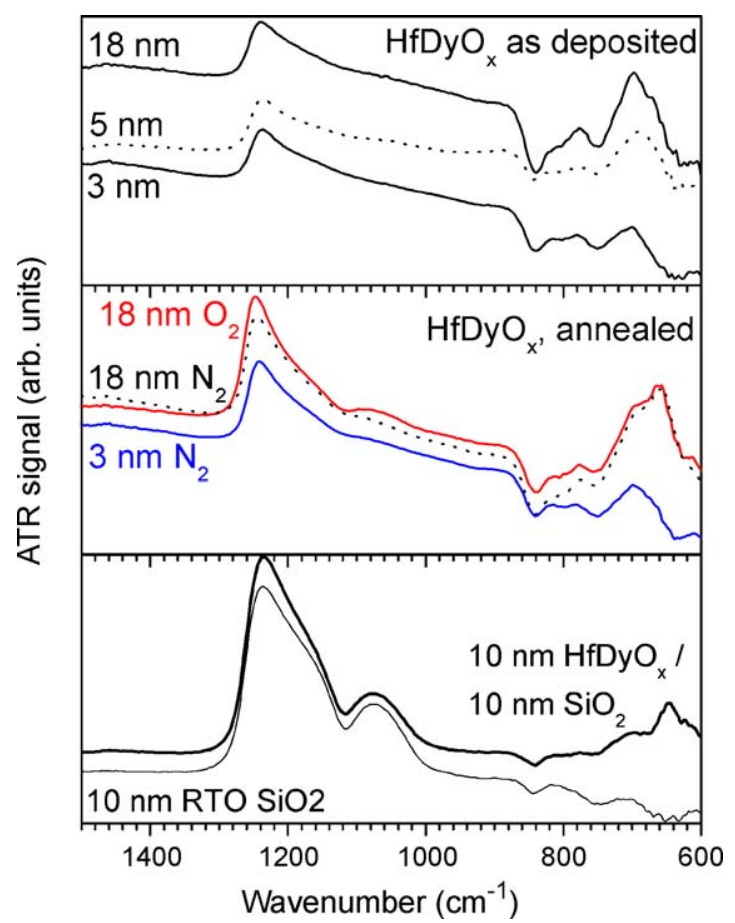

Fig. 3. GATR-FTIR spectra of $\mathrm{HfDyO}_{x}$ films, with thickness, deposited on substrates, with or without anneal as indicated.

reported earlier [6]. The cubic phase is stable during anneal in oxygen or nitrogen without transforming into the monoclinic phase. There is no evidence for silicate formation: in the region between 1250 and $1000 \mathrm{~cm}^{-1}$ the spectrum does not differ significantly from the blank substrate, both in the as-deposited films and after anneal. This is a large contrast with the results for $\mathrm{Dy}_{2} \mathrm{O}_{3}$ and $\mathrm{DyScO}_{3}$ (see further), both being characterized by strong silicate formation and contrasts with expectations for lanthanide containing oxides. Very recently, the high efficiency of $\mathrm{Hf}$ for suppression of silicate formation of $\mathrm{Dy}_{2} \mathrm{O}_{3}$ was also shown by investigation of silicate formation through ellipsometric thickness determinations, since only above $75 \%$ Dy content the silicate formation became pronounced [35]. Application of a thicker $\mathrm{SiO}_{2}$ starting surface for $\mathrm{HfDyO}_{x}$ growth, did not lead to silicate formation in $\mathrm{HfDyO}_{x}$ either, which is clear by comparison of $10 \mathrm{~nm}$ $\mathrm{HfDyO}_{x} / 10 \mathrm{~nm} \mathrm{SiO} 2$ with a blank $10 \mathrm{~nm} \mathrm{SiO} / 2 / \mathrm{Si}$ substrate. Like for the $1.1 \mathrm{~nm} \mathrm{SiO}{ }_{2}$ starting surface, a stabilized cubic phase $\mathrm{HfDyO}_{x}$ is formed on $10 \mathrm{~nm} \mathrm{RTO} \mathrm{SiO}_{2}$ as well. Annealing $\mathrm{HfDyO}_{x} 3 \mathrm{~nm}$ thick in $\mathrm{N}_{2}$ or $18 \mathrm{~nm}$ thick in $\mathrm{N}_{2}$ or $\mathrm{O}_{2}$ did not lead to significant changes as far as the phase or the absence of silicate is concerned. Since it can be expected that the thick films are completely crystallized after anneal, this further strengthens ascribing the band at $695 \mathrm{~cm}^{-1}$ to the cubic phase, together with the increased $k$-value and XRD pattern. The regrowth of the $\mathrm{SiO}_{2}$ interfacial layer is indicated by the increased intensity of the $\mathrm{SiO}_{2} \mathrm{LO}$ and TO bands after anneal in $\mathrm{O}_{2}$.

$\mathrm{HfScO}_{x}$ films of 3 and $8 \mathrm{~nm}$ grown on $1.1 \mathrm{~nm} \mathrm{SiO}_{2}$ are characterized as cubic phase as well, based on the absence of the typical vibration band around $780 \mathrm{~cm}^{-1}$ (Fig. 4). This is in agreement with X-ray diffraction [6]. Thicker films show an increased signal intensity, but the peak shape and position are constant, therefore the phase is stable independent of the film thickness in this range. Furthermore, there is no evidence for silicate formation, as the $\mathrm{SiO}_{2} \mathrm{LO}$ and $\mathrm{TO}$ region are similar to a blank substrate. $10 \mathrm{~nm} \mathrm{HfScO}_{x}$ grown on $10 \mathrm{~nm} \mathrm{SiO}_{x}$ substrates have the same crystal structure, and are resistant to silicate formation as well.

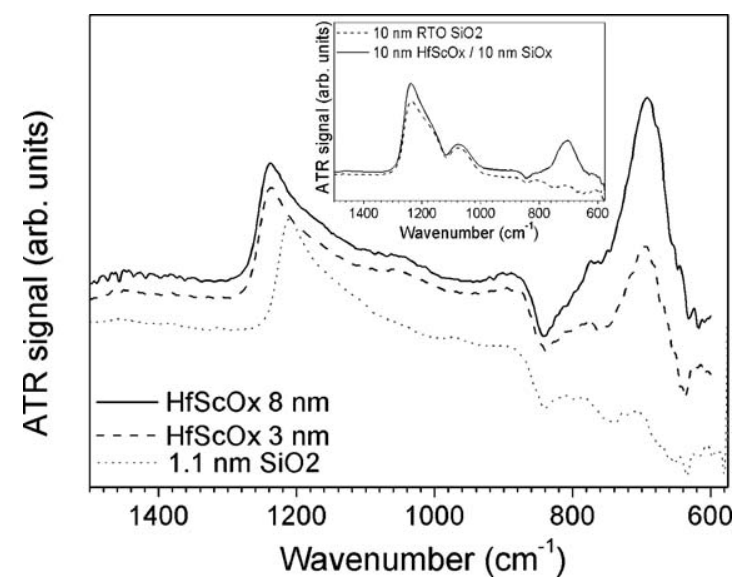

Fig. 4. GATR-FTIR spectra of $\mathrm{HfSCO}_{x}$ films with thickness and substrates as indicated.

Due to the stabilization of the cubic phase, the permittivity rose from 16 for pure $\mathrm{HfO}_{2}$ to 32 for Dy and Sc doped $\mathrm{HfO}_{2}$ [6] in accordance with Refs. [5,8].

\subsubsection{Interfacial reactions of dysprosium scandate}

$10 \mathrm{~nm} \mathrm{DyScO}{ }_{3}$ layers were deposited on $1.1 \mathrm{~nm} \mathrm{SiO}$ and $12 \mathrm{~nm}$ $\mathrm{HfO}_{2}$ substrates. The GATR-FTIR spectra (Fig. 5) show a strong, broad band with a maximum at $990 \mathrm{~cm}^{-1}$ for the $\mathrm{SiO}_{x}$ based film. This band gives evidence for the formation of $\mathrm{Si}-\mathrm{O}-\mathrm{Ln}$ silicate bonds. The band's shape and position resemble those of an analogous $\mathrm{Dy}_{2} \mathrm{O}_{3}$ film (Fig. 2). However, $\mathrm{DyScO}_{3}$ still has a larger shoulder at $1160 \mathrm{~cm}^{-1}$, indicating less interaction with $\mathrm{SiO}_{2}$ than for $\mathrm{Dy}_{2} \mathrm{O}_{3}$. The larger $\mathrm{Ln}^{3+}$ radius of $\mathrm{Dy}^{3+}$ compared to $\mathrm{Sc}^{3+}$ allows increased diffusion of $\mathrm{Si}$ from the substrate into $\mathrm{Dy}_{2} \mathrm{O}_{3}$ than $\mathrm{Sc}_{2} \mathrm{O}_{3}$ or $\mathrm{DySCO}_{3}$, leading to more $\mathrm{Si}-\mathrm{O}-\mathrm{Ln}$ bond formation [27]. Even though Ono et al. did not study $\mathrm{Sc}^{3+}$, it is possible that the trend continues for $\mathrm{Sc}^{3+}$ as well.

$10 \mathrm{~nm} \mathrm{DyScO}{ }_{3}$ was grown on $12 \mathrm{~nm} \mathrm{HfO}_{2}$ as well (Fig. 5). The presence of monoclinic $\mathrm{HfO}_{2}$ is confirmed by the vibration at $780 \mathrm{~cm}^{-1}$. Here, no evidence for silicate formation in the wavenumber region around $1050 \mathrm{~cm}^{-1}$ is found, indicating that $\mathrm{HfO}_{2}$ is acting as a buffer for Dy silicate formation, similar as for $\mathrm{Dy}_{2} \mathrm{O}_{3}$. A strong feature is observed at $635 \mathrm{~cm}^{-1}$, which overlaps with bands observed for hafnia and dysprosium scandate on $\mathrm{SiO}_{2} / \mathrm{Si}$.

Two vibrations are observed at 697 and $615 \mathrm{~cm}^{-1}$ for $\mathrm{DyScO}_{3} /$ $\mathrm{SiO}_{2} / \mathrm{Si}$ and they overlap with a band present for $\mathrm{DyScO}_{3}$ deposited on $\mathrm{HfO}_{2}$. These bands are absent for $\mathrm{Dy}_{2} \mathrm{O}_{3}$ as well as for the blank substrate, but close to the peak positions for the $\mathrm{Sc}_{2} \mathrm{O}_{3}$ film on

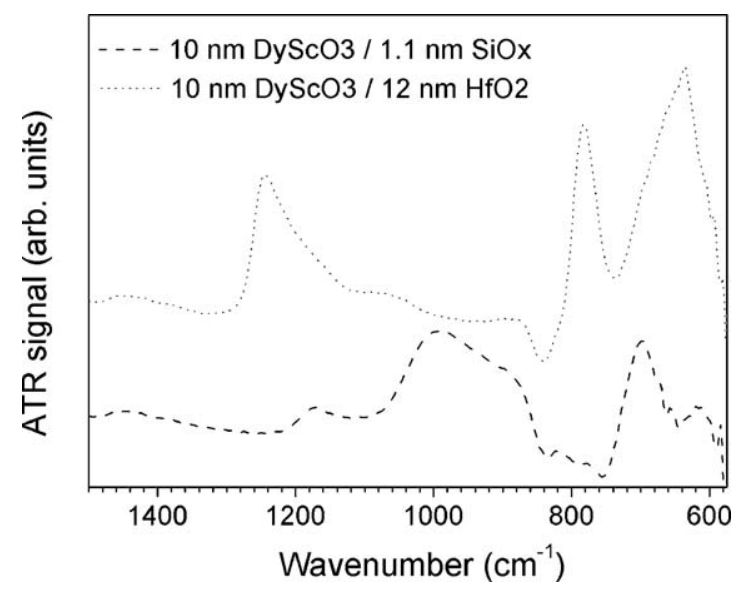

Fig. 5. GATR-FTIR spectra of $10 \mathrm{~nm} \mathrm{DyScO}{ }_{3}$ on substrates as indicated. 
$10 \mathrm{~nm} \mathrm{SiO}_{x}$. Therefore, these features might be typical $\mathrm{DyScO}_{3}$ vibrations, however, they are not derived from theory [38]. The wavenumber is also too high to be ascribed to pure $\mathrm{Dy}_{2} \mathrm{O}_{3}$ $\left(550 \mathrm{~cm}^{-1}\right)$ or $\mathrm{Sc}_{2} \mathrm{O}_{3}\left(635 \mathrm{~cm}^{-1}\right)$. However, according to literature, different crystalline lanthanide silicates show bands in the wavenumber region slightly below $700 \mathrm{~cm}^{-1}$ [39-41]. Based on the FTIR spectra reported here, $\mathrm{Dy}_{2} \mathrm{O}_{3}$ does not form this type of silicate but for $\mathrm{DyScO}_{3}$ and $\mathrm{Sc}_{2} \mathrm{O}_{3}$ it would be a possible explanation for the observations. Furthermore, recently it was reported in Ref. [9] that $12 \mathrm{~nm} \mathrm{DyScO} / 20 \mathrm{~nm} \mathrm{SiO}_{2} / \mathrm{Si}$ formed silicates after annealing at $1000^{\circ} \mathrm{C}$. A crystalline Sc-rich (Dy,Sc)-silicate was found at the top surface, while at the bottom interface with the substrate an amorphous, Sc-poor Dy-rich silicate was found. These different types of silicate formation may therefore explain the GATR-FTIR observations made here.

\subsubsection{Conclusions}

GATR-FTIR allows a highly sensitive, inexpensive and fast characterization of ultrathin metal oxide layers with different compositions. Insights in chemical purity, interfacial reactions and crystal phases are obtained, which contribute to the understanding of the high- $k$ material's dielectric properties, complementary to more complicated, often destructive analyses.

Interfacial reactions leading to silicate formation, were demonstrated in $\mathrm{Dy}_{2} \mathrm{O}_{3}$ and $\mathrm{DyScO}_{3}$. A thin $\mathrm{SiO}_{2}$ interlayer was shown to be entirely consumed by the silicate formation, while deposition of a $\mathrm{HfO}_{2}$ buffer layer prevented the interfacial reaction. On the other hand $\mathrm{HfO}_{2}, \mathrm{HfSCO}_{x}$ and $\mathrm{HfDyO}_{x}$ layers were silicatefree, independent of the substrate's $\mathrm{SiO}_{2}$ thickness or the anneal treatment.

Finally, GATR-FTIR was shown to be highly sensitive to monoclinic $\mathrm{HfO}_{2}$, and surpasses deep UV micro-Raman measurement. GATR-FTIR demonstrated that doping hafnia with Dy or Sc, prevents crystallization of the monoclinic hafnia phase. The improved permittivity of the doped films can be ascribed to the formation of the cubic phase.

\section{Acknowledgements}

A. Hardy and M.K. Van Bael are postdoctoral research fellows of the Research Foundation Flanders (FWO-Vlaanderen). This study was supported by the FWO research project G.0273.05. The authors thank Dr. R. Lewandowska at Horiba Jobin Yvon, Villeneuve d'Ascq, for the deep UV micro-Raman measurements of $\mathrm{HfO}_{2}$ films.

\section{References}

[1] J. Robertson, High dielectric constant gate oxides for metal oxide Si transistors, Rep. Prog. Phys. 69 (2006) 327-396.

[2] G.D. Wilk, R.M. Wallace, J.M. Anthony, High-kappa gate dielectrics: current status and materials properties considerations, J. Appl. Phys. 89 (2001) 52435275.

[3] D. Ceresoli, D. Vanderbilt, Structural and dielectric properties of amorphous $\mathrm{ZrO}_{2}$ and $\mathrm{HfO}_{2}$, Phys. Rev. B 74 (2006) 125108.

[4] X.Y. Zhao, D. Vanderbilt, First-principles study of structural, vibrational, and lattice dielectric properties of hafnium oxide, Phys. Rev. B 65 (2002) 233106.

[5] K. Kita, K. Kyuno, A. Toriumi, Permittivity increase of yttrium-doped $\mathrm{HfO}_{2}$ through structural phase transformation, Appl. Phys. Lett. 86 (2005) 102906.

[6] C. Adelmann, V. Sriramkumar, S. Van Elshocht, P. Lehnen, T. Conard, S. De Gendt, Dielectric properties of dysprosium- and scandium-doped hafnium dioxide thin films, Appl. Phys. Lett. 91 (2007) 162902.

[7] E. Rauwel, C. Dubourdieu, B. Hollander, N. Rochat, F. Ducroquet, M.D. Rossell, G. Van Tendeloo, B. Pelissier, Stabilization of the cubic phase of $\mathrm{HfO}_{2}$ by $\mathrm{Y}$ addition in films grown by metal organic chemical vapor deposition, Appl. Phys. Lett. 89 (2006) 012902

[8] S. Govindarajan, T.S. Boscke, P. Sivasubramani, P.D. Kirsch, B.H. Lee, H.H. Tseng, R. Jammy, U. Schroder, S. Ramanathan, B.E. Gnade, Higher permittivity rare earth doped $\mathrm{HfO}_{2}$ for sub-45-nm metal-insulator-semiconductor devices, Appl. Phys. Lett. 91 (2007) 062906.
[9] C. Adelmann, S. Van Elshocht, A. Franquet, T. Conard, O. Richard, H. Bender, P. Lehnen, S. De Gendt, Thermal stability of dysprosium scandate thin films, Appl. Phys. Lett. 92 (2008) 112902

[10] C. Zhao, T. Witters, B. Brijs, H. Bender, O. Richard, M. Caymax, T. Heeg, J. Schubert V.V. Afanas'ev, A. Stesmans, D.G. Schlom, Ternary rare-earth metal oxide high- $k$ layers on silicon oxide, Appl. Phys. Lett. 86 (2005) 132903.

[11] M.L. Green, M.Y. Ho, B. Busch, G.D. Wilk, T. Sorsch, T. Conard, B. Brijs, W. Vandervorst, P.I. Raisanen, D. Muller, M. Bude, J. Grazul, Nucleation and growth of atomic layer deposited $\mathrm{HfO}_{2}$ gate dielectric layers on chemical oxide ( $\mathrm{Si}-\mathrm{O}-\mathrm{H}$ ) and thermal oxide $\left(\mathrm{SiO}_{2}\right.$ or $\left.\mathrm{Si}-\mathrm{O}-\mathrm{N}\right)$ underlayers, J. Appl. Phys. 92 (2002) 7168 7174.

[12] L. Nyns, A. Delabie, M. Caymax, M.M. Heyns, S. Van Elshocht, C. Vinckier, S. De Gendt, $\mathrm{HfO}_{2}$ atomic layer deposition using $\mathrm{HfCl}_{4} / \mathrm{H}_{2} \mathrm{O}$ : the first reaction cycle, J. Electrochem. Soc. 155 (2008) G269-G273.

[13] L. Nyns, L. Hall, T. Conard, A. Delabie, W. Deweerd, M. Heyns, S. Van Elshocht, N. Van Hoornick, C. Vinckier, S. De Gendt, Nucleation and growth behavior of atomic layer deposited $\mathrm{HfO}_{2}$ films on silicon oxide starting surfaces, J. Electrochem. Soc. 153 (2006) F205-F209.

[14] S. Miyazaki, H. Nishimura, M. Fukuda, L. Ley, J. Ristein, Structure and electronic states of ultrathin $\mathrm{SiO}_{2}$ thermally grown on $\mathrm{Si}\left(\begin{array}{lll}1 & 0 & 0\end{array}\right)$ and $\mathrm{Si}\left(\begin{array}{lll}1 & 1 & 1\end{array}\right)$ surfaces, Appl. Surf. Sci. 114 (1997) 585-589.

[15] N. Rochat, A. Chabli, F. Bertin, M. Olivier, C. Vergnaud, P. Mur, Attenuated total reflection spectroscopy for infrared analysis of thin layers on a semiconductor substrate, J. Appl. Phys. 91 (2002) 5029-5034.

[16] N. Rochat, K. Dabertrand, V. Cosnier, V. Zoll, P. Besson, U. Weber, Infrared spectroscopy of high $k$ thin layer by multiple internal reflection and attenuated total reflection, Phys. Stat. Sol. (c) 0 (2003) 2961-2965.

[17] C. Adelmann, P. Lehnen, S. Van Elshocht, C. Zhao, B. Brijs, A. Franquet, T. Conard, M Roeckerath, J. Schubert, O. Boissière, C. Lohe, S. De Gendt, Growth of dysprosium-, scandium-, and hafnium-based third generation high-dielectrics by atomic vapor deposition, Chem. Vapor Depos. 13 (2007) 567-573.

[18] R. Thomas, P. Ehrhart, M. Roeckerath, S. Van Elshocht, E. Rije, M. Luysberg, M. Boese, J. Schubert, M. Caymax, R. Waser, Liquid injection MOCVD of dysprosium scandate films - deposition characteristics and high- $k$ applications, J. Electrochem. Soc. 154 (2007) G147-G154.

[19] M.A. Quevedo-Lopez, J.J. Chambers, M.R. Visokay, A. Shanware, L. Colombo, Thermal stability of hafnium-silicate and plasma-nitrided hafnium silicate films studied by Fourier transform infrared spectroscopy, Appl. Phys. Lett. 87 (2005) 012902.

[20] N. Nagai, H. Hashimoto, FT-IR-ATR study of depth profile of $\mathrm{SiO}_{2}$ ultra-thin films, Appl. Surf. Sci. 172 (2001) 307-311.

[21] D.P. Zarubin, The two-component bands at about 4500 and $800 \mathrm{~cm}^{-1}$ in infrared spectra of hydroxyl-containing silicas. Interpretation in terms of Fermi resonance, J. Non-Cryst. Solids 286 (2001) 80-88.

[22] C. Dubourdieu, H. Roussel, C. Jimenez, M. Audier, J.P. Senateur, S. Lhostis, L. Auvray, F. Ducroquet, B.J. O'Sullivan, P.K. Hurley, S. Rushworth, L. Hubert-Pfalzgraf, Pulsed liquid-injection MOCVD of high-K oxides for advanced semiconductor technologies, Mater. Sci. Eng. B: Solid State Mater. Adv. Technol. 118 (2005) $105-111$.

[23] D.A. Neumayer, E. Cartier, Materials characterization of $\mathrm{ZrO}_{2}-\mathrm{SiO}_{2}$ and $\mathrm{HfO}_{2}-\mathrm{SiO}_{2}$ binary oxides deposited by chemical solution deposition, J. Appl. Phys. 90 (2001) 1801-1808.

[24] C. Dubourdieu, E. Rauwel, C. Millon, P. Chaudouet, F. Ducroquet, N. Rochat, S. Rushworth, V. Cosnier, Growth by liquid-injection MOCVD and properties of $\mathrm{HfO}_{2}$ films for microelectronic applications, Chem. Vapor Depos. 12 (2006) 187-192

[25] D. Dubourdieu, S. Van Elshocht, C. Adelmann, in WoDiM Workshop on Dielectrics in Microelectronics, Bad Saarow (Berlin), 2008, personal communication.

[26] A. Delabie, G. Pourtois, M. Caymax, S. De Gendt, L.A. Ragnarsson, M. Heyns, Y. Fedorenko, J. Swerts, J.W. Maes, Atomic layer deposition of hafnium silicate gate dielectric layers, J. Vac. Sci. Technol. A 25 (2007) 1302-1308.

[27] H. Ono, T. Katsumata, Interfacial reactions between thin rare-earth-metal oxide films and Si substrates, Appl. Phys. Lett. 78 (2001) 1832-1834.

[28] W.L. Baun, N.T. McDevitt, Infrared absorption spectra of rare-earth oxides in the region 800 to $240 \mathrm{~cm}^{-1}$, J. Am. Ceram. Soc. 46 (1963) 294-1294.

[29] N.T. McDevitt, W.L. Baun, Infrared absorption study of metal oxides in the low frequency region (700-240 $\mathrm{cm}^{-1}$ ), Spectrochim. Acta 20 (1964) 799-808.

[30] N.T. McDevitt, A.D. Davidson, Infrared lattice spectra of cubic rare earth oxides in region 700 to $50 \mathrm{~cm}^{-1} 56$ (1966) 636 .

[31] D.B. Faithful, S.M. Johnson, I.J. McColm, Infrared-spectra of lanthanide sesquioxides 10 (1973) 291-302.

[32] H. Vidal, S. Bernal, R.T. Baker, D. Finol, J.A.P. Omil, J.M. Pintado, J.M. RodriguezIzquierdo, Characterization of $\mathrm{La}_{2} \mathrm{O}_{3} / \mathrm{SiO}_{2}$ mixed oxide catalyst supports, J. Catal. 183 (1999) 53-62.

[33] N.B. Colthup, L.H. Daly, S.E. Wiberley, Introduction to Infrared and Raman Spectroscopy, third ed., Academic Press, San Diego, 1990.

[34] S. Jeon, H.S. Hwang, Effect of hygroscopic nature on the electrical characteristics of lanthanide oxides $\left(\mathrm{Pr}_{2} \mathrm{O}_{3}, \mathrm{Sm}_{2} \mathrm{O}_{3}, \mathrm{Gd}_{2} \mathrm{O}_{3}\right.$, and $\left.\mathrm{Dy}_{2} \mathrm{O}_{3}\right)$, J. Appl. Phys. 93 (2003) 6393-6395.

[35] S. Van Elshocht, C. Adelmann, T. Conard, A. Delabie, A. Franquet, L. Nyns, O. Richard, P. Lehnen, J. Swerts, S. De Gendt, Silicate formation and thermal stability of ternary rare earth oxides as high- $k$ dielectrics, J. Vac. Sci. Technol. A 26 (2008) 724-730.

[36] W.B. White, V.G. Keramidas, Vibrational-spectra of oxides with C-type rare-earth oxide structure, Spectrochim. Acta A A28 (1972) 501.

[37] S.J. Schneider, J.L. Waring, Phase equilibrium relations in the $\mathrm{Sc}_{2} \mathrm{O}_{3}-\mathrm{Ga}_{2} \mathrm{O}_{3}$ system, J. Res. Nat. Bur. Stand. A 67A (1963) 19-25. 
[38] P. Delugas, V. Fiorentini, A. Filippetti, G. Pourtois, Cation charge anomalies and high-kappa dielectric behavior in DySc03: ab initio density-functional and selfinteraction-corrected calculations, Phys. Rev. B 75 (2007) 115126.

[39] L. Kepinski, M. Maczka, M. Drozd, Formation and characterization of Lu silicate nanoparticles in amorphous $\mathrm{SiO}_{2}$, J. Alloy. Compd. 443 (2007) 132-142.
[40] L. Kepinski, M. Wolcyrz, M. Drozd, Interfacial reactions and silicate formation in highly dispersed $\mathrm{Nd}_{2} \mathrm{O}_{3}-\mathrm{SiO}_{2}$ system, Mater. Chem. Phys. 96 (2006) 353-360.

[41] L. Kepinski, W. Mista, J. Okal, M. Drozd, M. Maczka, Interfacial reactions and silicate formation in high surface $\mathrm{SiO}_{2}$ impregnated with La nitrate, Solid State Sci. 7 (2005) 1300-1311. 